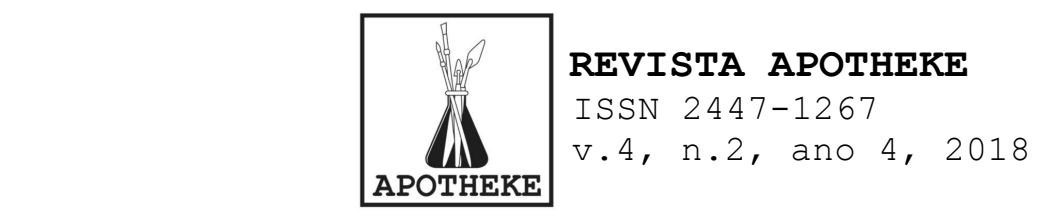

\title{
Entre arte e cultura visual: possibilidades conceituais nos discursos contemporâneos
}

\author{
Milena Regina Duarte Corrêa (UFSM) \\ Jéssica Maria Freisleben (UFSM)
}

\begin{abstract}
RESUMO
Esse texto propõe relações conceituais entre arte e cultura visual que são possíveis nos discursos da contemporaneidade. Tem objetivo de pensar como o campo legitimado, estruturado e canônico da arte, pode se relacionar com as propostas relativistas, interpretativas e não universais da cultura visual. Da mesma forma, tem interesse em pensar a educação das artes a partir de uma abordagem sem linhas pré-definidas e que propõe um posicionamento crítico. Escrevendo a partir da cultura visual, leva também em consideração as imagens oriundas de diversas fontes e os artefatos visuais que os estudantes carregam para a sala de aula. Dessa forma, acredita-se que o texto mobiliza refletir sobre aquilo que já está definido, mas a partir de um outro lugar de fala que a contemporaneidade permite, esse lugar de discursos múltiplos, variáveis e não universais que é a perspectiva da cultura visual.
\end{abstract}

PALAVRAS-CHAVE: Arte; educação; cultura visual; contemporaneidade.

\section{RESUMEM}

Este texto propone relaciones conceptuales entre arte y cultura visual que son posibles en los discursos de la contemporaneidad. Tiene el objetivo de pensar cómo el campo legitimado, estructurado y canónico del arte, puede relacionarse con las propuestas relativistas, interpretativas y no universales de la cultura visual. De la misma forma, tiene interés en pensar la educación de las artes a partir de un enfoque sin líneas predefinidas y que propone un posicionamiento crítico. Escribiendo a partir de la cultura visual, toma también en consideración las imágenes oriundas de diversas fuentes y los artefactos visuales que los estudiantes cargan al aula. De esta forma, se cree que el texto moviliza reflexionar sobre lo que ya está definido, pero a partir de otro lugar de habla que la contemporaneidad permite, ese lugar de discursos múltiples, variables y no universales que es la perspectiva de la cultura visual.

PALABRAS CLAVE: Arte; educación; cultura visual; contemporaneidad.

\section{Arte e História variável: possibilidades de discurso}

As direções sugeridas pela contemporaneidade possibilitam que campos conceituais, por vezes considerados antagônicos, se atravessem. Esse subcapítulo tem intenção de refletir como os campos conceituais legitimados, estruturados e canônicos da arte e de sua história podem ser revistos pelo olhar plural e interpretativo da cultura visual.

O desenvolver da ideia de revisão das estruturas universais da arte se dissipou com O fim da história da arte, 


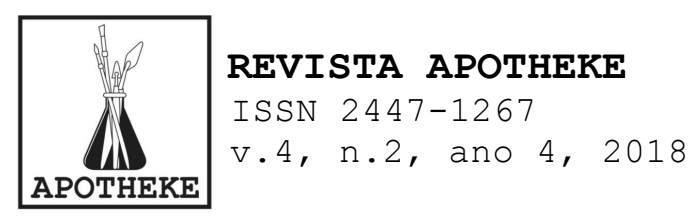

de Hans Belting (2006), quando, para o autor, o que acaba são os enquadramentos e as regras que direcionavam as estruturas da história da arte, um fim que chegou àqueles que não viam sentido na história vigente e não sentiam-se contemplados. A partir disso, aproximamo-nos de Keith Moxey (2001), que em seus ensaios procura revisitar a história a partir de outros enfoques, pensando que ela foi escrita em determinado local e cultura, atrelada à época de sua criação e, por isso, não poderia ser considerada universal. Dessa forma, pensa-se em várias histórias com vários métodos que se relacionam com as direções sugeridas pela contemporaneidade, esta que é proposta por micro-discursos, pequenos relatos que descaracterizam a perspectiva evolutiva e homogênea da arte.

A abordagem da história da arte como um território de probabilidades e abertura para interpretações permite superar os dilemas elitistas para pensar em uma pós-história interdisciplinar, interpretativa e relativista. É nisso o que, de fato, centra-se o estudo da cultura visual: uma abordagem que não quer renunciar a filosofia da história, mas pensá-la a partir da diferença e multiplicidade cultural, um movimento que abre o estudo da história para que os relatos sejam mais interessantes. (MOXEY, 2001).

Dialogando com Moxey, Mirzoeff (1999), diz que autores da teoria, história e crítica da arte contestaram a cultura visual como ameaça potencial para a arte como instituição, justamente por se tratar de uma história múltipla, que se transforma em história das imagens de um modo híbrido e desafiador. Para outros, a cultura visual foi como um espaço de mobilidade que proporcionava uma ruptura decisiva nas práticas que antes eram restritivas. Para Guash (2005), optar pelo termo "cultura" propõe modelos mais sincrônicos que garantem flexibilidade e contemplem diferentes públicos, preocupando-se mais com o significado cultural, do que com o valor estético. 


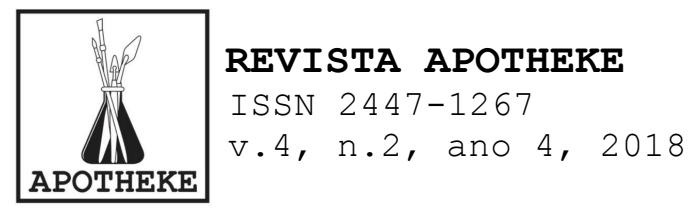

Mesmo que a cultura visual tente evitar a abordagem da história por linhas pré-definidas, é importante salientar que para os autores aqui contemplados, não se trata de uma renúncia a tudo aquilo que conhecemos e que foi legitimado. o valor das categorias aqui pensadas, está na justaposição de ambos os discursos, tanto da arte e sua história, como da cultura visual, a fim de perceber como podem se relacionar e o modo que seus estudiosos transitam entre os campos e dão significados críticos a cada uma das proposições. Da mesma forma, não é necessário fundir essas categorias, suas distinções quando mantidas podem vir a alcançar suas potencialidades. Já que, assumindo a sua diferença metodológica, percebem-se os benefícios de colocá-las em relação, deve-se levar em conta também que, atualmente, as atitudes teóricas sugerem que a contribuição mais forte no campo do conhecimento se faz na diferença e não na igualdade. (MOXEY, 2001).

Tendo em vista a possibilidade de revisitar a arte e sua história e renovar nosso modo de olhar para aquilo que está consagrado, pensemos na grande contribuição de colocar em relação campos conceituais tão abrangentes, reconhecendo sua heterogeneidade - levando em conta que a história da arte prioriza obras legitimadas e, a cultura visual, qualquer tipo de imagem - e mesmo assim, torna possível um diálogo aberto a qualquer tipo de discurso que priorize as imagens como portadoras de significados e posições discursivas.

Levando em consideração que a cultura visual interessa-se por todas as visualidades que compõem o cenário contemporâneo, Moxey (2001) sugere que ela tenha um conjunto de ferramentas críticas para a investigação da visualidade humana - o que, antigamente, tínhamos como "apreciação da arte"- e que há uma série de conceitos para aproximar-se do mundo da experiência visual. Mesmo assim, entende-se que mais do que meios para tal, é mais pertinente refletir sobre como as imagens são 


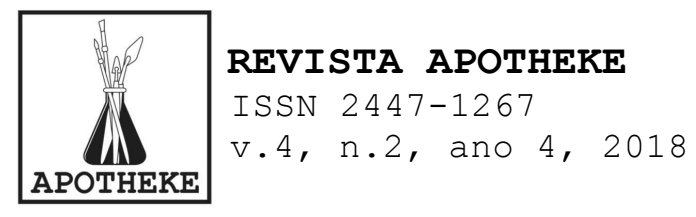

práticas culturais que produzem diferentes significados e proporcionam distintas interpretações para cada um que venha a se relacionar com elas.

Já que essa categoria permite expandir os objetos individuais, as obras de arte e todo o universo de representações visuais, é necessário que a história da arte redefina seu estatuto fechado e amplie suas condições canônicas. Para Guash (2005), essa proposta interconecta o objeto visual e seu contexto, e considera que o importante não é desvelar o significado da imagem ou seu valor cultural, mas a maneira com que requisita diferentes posições de olhares críticos que conduzam a uma série de experiências visuais.

Por esse motivo, entende-se que a cultura visual constitui-se a partir de outra perspectiva que não considera somente o valor estético - o qual não se perde, mas é investido de outros poderes que se relacionam ao seu contexto social - mas o papel dessa imagem na vida e cultura das pessoas. Ter a oportunidade de reavaliar as coisas por outro ângulo implica transcender o comodismo de análise compositiva de uma imagem, para um gesto crítico e sensível.

Alguns críticos argumentam contra o estudo, avaliando que parece ser uma mistura de interesses, direções e estilos fragmentados. Entretanto, entende-se que as direções que a contemporaneidade sugere suscitam o imediatismo de renunciar ao impulso de dominar e ajustar a arte a um modelo, incorporando um momento de encontro com outros modelos de análise. O espaço conceitual é móvel, convergente, híbrido, congrega discussões sobre aspectos diversificados e desafia os limites e as práticas sistemáticas da arte como instituição. Por isso, representa parte das inquietações e das movimentações que estão acontecendo na contemporaneidade. 


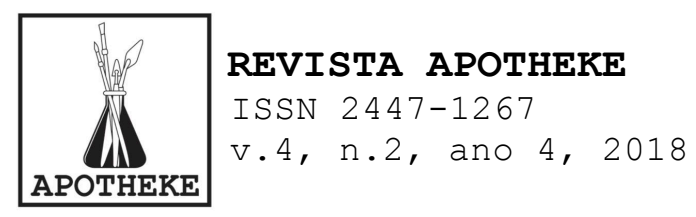

Sendo assim, a ampla proposição da cultura visual como campo de pesquisa está na sua possibilidade de intercessão entre áreas conceituais que divergem, com objetivo de dialogar e produzir sentido com aquilo que já se tem, além de acrescentar outras inquietações que podem não ter relação. De acordo com Nascimento,

\begin{abstract}
falar em transdisciplinaridade é uma maneira de reconhecer como o campo da Cultura Visual é alimentado e se efetiva mediante a articulação de diferentes saberes para compreender os efeitos e o poder dos processos de subjetivação exercidos pelas imagens, especialmente na contemporaneidade. Reconhece-se que uma atitude transdisciplinar favorece a ampliação e a flexibilização dos conhecimentos, gerando novos saberes oportunizados pela pluralidade de ângulos que um determinado problema é capaz de proporcionar (NASCIMENTO, 2011, p. 210).
\end{abstract}

Por isso, beber da fonte da cultura visual como oportunidade para retornar nossa maneira de ver a história da arte universal, constitui o principal objetivo da contemporaneidade em questionar o que está posto, a partir de uma movimentação subjetiva e alterável. Dessa forma, a perspectiva aqui apresentada ajuda a fundamentar um discurso contemporâneo que promove o diálogo entre conceitos fundamentalmente diferentes, mas que tem potencial de ser reinterpretados e variáveis conforme as posições que os assumem.

\title{
Educação e Cultura Visual
}

Partindo do pressuposto que nos deparamos com imagens diariamente nas mais variadas relações e contextos, pensar os efeitos das imagens sobre nós, como fabricamos nossos conceitos, conhecimentos, significações, valores, visualidades, pontos de vista sobre o mundo a partir da cultura visual, sinaliza nossa capacidade emancipatória de escolha frente aos discursos e torna-se fundamental em ambientes educativos, desde cedo. 


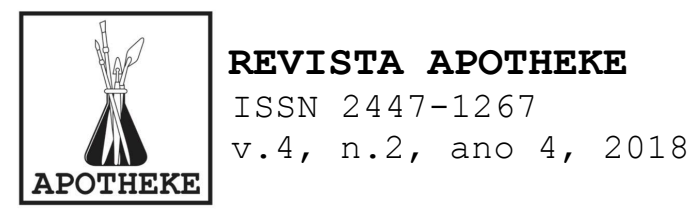

Nesse sentido, as teorias referentes ao campo transdisciplinar da cultura visual podem se relacionar com a ideia de "fazer ver" o que não está posto de forma literal. Os estudos em cultura visual propõem, em seu ramo mais crítico, uma postura diferenciada referente às maneiras pelas quais olhamos e nos relacionamos com os artefatos e processos que envolvem as imagens e as visualidades. Assim, de alguma forma, adotar a cultura visual é também, pensar sobre o que não se está vendo diretamente. Hernández (2013), assinala que,

\begin{abstract}
em um mundo dominado por dispositivos da visão e tecnologias do olhar, a finalidade que proponho com a pesquisa com e sobre imagens a partir da Cultura Visual é explorar nossa relação com as práticas do olhar, as relações de poder em que somos colocados e questionar as representações que construímos a partir de nossas relações com os outros, pois, afinal, se não podemos compreender o mundo e intervir nele é porque não temos a capacidade de repensá-lo e oferecer alternativas aos relatos naturalizados. (HERNÁNDEZ, 2013, p. 92).
\end{abstract}

O campo da cultura visual possibilita uma extensa gama de discussões e questionamentos a respeito das imagens na atualidade e a relação ou não destas com o passado e, se, atrelado ao campo educacional pode ser potente em práticas e reflexões contextualizadas. Possibilita repensar nossas posições no mundo, questionar as relações de poder que são exercidas sobre nós vinculadas pelas imagens. O consumo e acesso às elas faz parte do dia a dia e confirma que, na atualidade, a sociedade é altamente visual. De acordo com Hernández,

- debate do que denominamos por cultura visual, converge uma série de propostas intelectuais em termos das práticas culturais relacionadas ao olhar e às maneiras culturais de olhar na vida contemporânea, especialmente sobre as práticas que favorecem as representações de nosso tempo e leva-nos a repensar as narrativas do passado. (HERNÁNDEZ 2007, p. 22).

Dessa forma, favorecer práticas culturais que desestabilizem noções naturalizadas apresenta-se como fundamental na atitude contemporânea. Entretanto, é necessário 


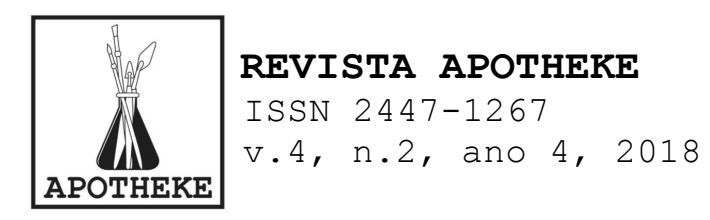

entender que na escola, a intenção não é ensinar 'o que ver e como ver', mas estimular o estudante a questionar o que vê, problematizar as relações que têm com o mundo e as formas de compreensão deste mesmo mundo por meio das visualidades e da interpretação crítica.

Sendo assim, entende-se que na escola, podemos exercitar práticas que nos levem a não ser passivos diante das imagens e de tudo que a mídia homogeneizadora tenta impor. A partir dessas outras possibilidades, aproximamo-nos da ideia de "catadora contemporânea" termo cunhado por Hernández (2007), em seu livro "Catadores da Cultura Visual". Igualmente dos termos "professor/professora bricoleur", com a intenção de catar/compor com os fragmentos da cultura visual e ressignificar/recriar narrativas nos espaços que transitamos. O/a professor/professora bricoleur trabalha a partir do que o seu contexto dispõe, as imagens que nele surgirem de modo a articular possibilidades de criar outras narrativas com seus estudantes. Essa alternativa é pensada com intuito de ressignificar o que o próprio contexto apresenta, para que os/as estudantes possam ter a experiência do pensamento crítico e reflexivo diante daquilo que já está posto e consumado.

Tendo em vista a notoriedade de acesso das pessoas às imagens cotidianas, é que a cultura visual justifica-se como potência para pensar essas imagens - já que se tem mais contato com elas do que com produções artísticas, pois o acesso vem sendo facilitado pelo/com o uso das novas tecnologias que promovem maior circulação e consumo. Aquilo que está instituído socialmente como arte continua sendo algo distante para a maioria dos(as) estudantes e até mesmo professores(as), por isso, historicamente, a escola acaba não se aproximando dos assuntos do cotidiano, assim como de suas imagens. Porém, longe de querer abolir as produções artísticas 


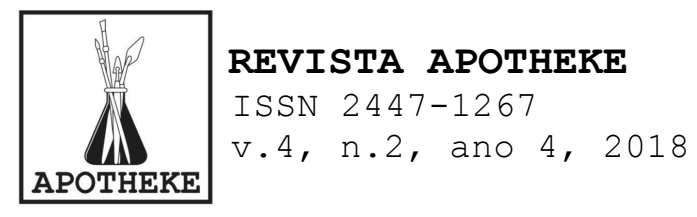

e imagens de obras instituídas - pois para alguns/algumas estudantes poderá ser o único contato com essas imagenspretende-se ampliar e problematizar também as o que aparece no seu entorno e as visualidades que o compõe. E por que não fazer disso um disparador para pensar a Arte?

Diante disto, uma das alternativas em sala de aula, pode ser a proposição de experimentações artísticas que tomem como ponto de partida imagens oriundas da grande mídia, seja ela para ação pedagógica tanto com crianças, como adolescentes.

Sendo assim, entendemos também que as experimentações de cunho mais tradicional, explorando materiais, aproximando-se de obras e artistas consagrados e a busca por produções singulares, continuarão presentes na escola. O que se amplia é a oferta de imagens, que podem vir a ser da cultura midiática, pois fazem parte da vida da maioria dos/as estudantes, uma vez que as produções televisivas, fílmicas, publicitárias, da web, entre outras produções culturais participam efetivamente da vida das crianças, de seus imaginários, criando modos de ser e relacionar-se com 0 mundo. Essas imagens cotidianas exercem algum tipo de atração que nos envolve e seduz. Como aponta Giroux (1995, p. 62), "o poder visual destas imagens é tão intenso e convincente que há uma adesão admirativa quase que imediata e, em função disto sequer são questionados seus significados". E, nas crianças e adolescentes, esse efeito não seria diferente, pelo contrário, é potencializado desde a mais tenra idade. Assim sendo, como negligenciar essa satisfação estética e o deleite afetivo que a maioria dos/as estudantes têm com os artefatos culturais populares? Porque não problematizar seus significados e criar, a partir desses mesmos artefatos, outras narrativas que possam contradizê-los?

Entendemos que nosso posicionamento diante de imagens é mutável, e torna-se imprescindível adotar um olhar de desconfiança ao que nos é mostrado, ou não. Diante dessas verificações, e muitas outras, buscamos ampliar as discussões 


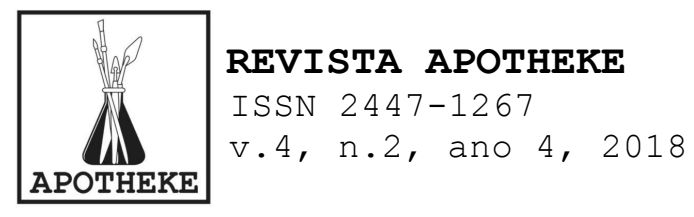

e reflexões sobre as imagens e os efeitos delas sobre nós, entendendo as produções da arte como mais uma das possibilidades da cultura visual. Como apontam Tourinho e Martins

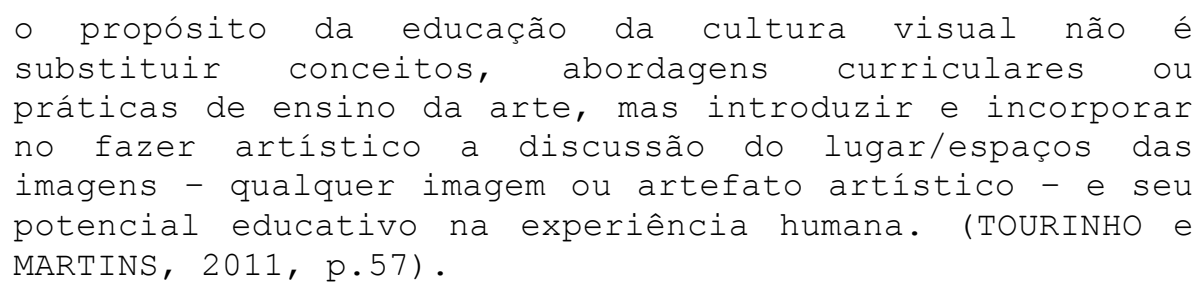

Diante dos apontamentos apresentados, talvez seja relevante aos processos pedagógicos da escola problematizar o repertório visual escolhido pelos(as) estudantes, incentivando-as a questionar, atentar ao que lhes é imposto, às imagens que selecionam, bem como aquelas que são deixadas de lado. Conforme apontado por Buckingham (2002), talvez a ideia primordial não seja discutir sobre proteger as crianças dos males das mídias, mas pensar como elas poderiam preparar as crianças mais efetivamente para as responsabilidades da cidadania adulta - ou mesmo habilitá-las a intervir nas decisões políticas que governam suas vidas de criança. Além disso, instigá-las a pensar (por meio da experiência estética/visual/afetiva) como são suas perspectivas frente ao mundo e às relações que estabelecem com seus pares. Isso se justifica, pois, para muitas destas, a escola constitui-se um dos únicos espaços onde pode exercitar sua autonomia e/ou negociação com a diversidade de opiniões e posicionamentos.

Muito mais do que enfocar os artefatos visuais, a Cultura Visual preocupa-se com 0 modo de produção das imagens, distribuição e utilização social, como uma prática cultural que produz e negocia significados.

É necessário, esclarecer que, ao mencionarmos "cultura visual", estamos pisando em um terreno ainda bastante movediço, já que refere-se a estudos que emergiram, de acordo com o que nos revela Hernández (2007), no final dos anos 80, 


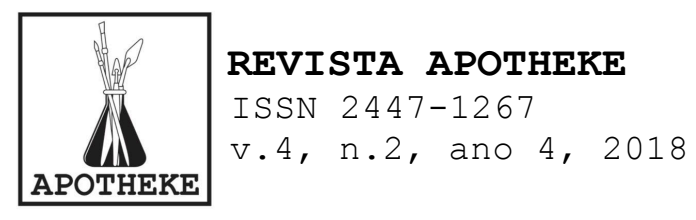

um debate que entremeia discussões de áreas múltiplas como a cultura da mídia, a história da arte, estudos da sociologia da cultura, da área do cinema, da linguística, dos estudos visuais e culturais, dentre outros. De acordo com a perspectiva do autor, o campo da cultura visual apareceu para problematizar as relações e os posicionamentos sobre os mais diversos tipos de imagens. Conforme apontado por salbego (2017),

estes estudos emergem, assim, como resultado de uma
condição histórica em que a produção de bens materiais e
simbólicos aumenta progressivamente em função dos
desenvolvimentos tecnológicos e das tecnologias de
comunicação e nas quais outras disciplinas mais antigas
como a estética e história da arte (tradicionalmente
'detentores deste conhecimento') já não podiam dar
conta. (SALBEGo, $2017 \mathrm{p} .28$ ).

Dentro desse contexto emergente, torna-se interessante também diferenciar imagem e visualidade. De acordo com Salbego (2017), a visualidade difere da imagem na medida em que se refere ao processo que envolve uma experimentação (das imagens em seus mais diversos tipos) e toda a gama de valores, sentidos e emoções que movimenta no processo. As imagens, por si só, são inertes, mas é o movimento de relação estabelecido a partir do sujeito que produz a visualidade. Diante essa distinção, podemos pensar em imagens como disparadoras para esse processo de experimentação que podem estar presentes na escola desde cedo.

A partir dessa virada, entende-se que a relação entre imagem/artefato e sujeito é o que interessa, e não há nenhum tipo de "poder" na obra em si. A partir do presente alargamento de possibilidades, pode-se tomar como apropriação simbólica tanto um quadro consagrado na História da Arte, quanto um anúncio publicitário, pois o que está em jogo não é - que esse artefato 'carrega consigo', mas a experimentação que aquele sujeito faz dele e como isso muda o sujeito consumidor. 


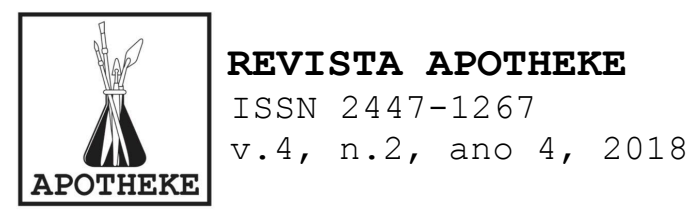

Essa nova necessidade surge com os avanços tecnológicos e a imensidão de imagens, principalmente, do ensino de artes, pois este foi adotado como disciplina que trabalha com as imagens. Pensando na prática docente com crianças, quem pode desempenhar esse papel é o/a professor(a) unidocente, ao explorar práticas expressivas estabelecendo aproximações com as imagens que também fazem parte dos repertórios das crianças. Por isso, é questionável insistir apenas em práticas consagradas, como o desenho e pintura, diante de crianças que, desde cedo, convivem e manipulam imagens digitais. A questão novamente é de acréscimo, de ampliação de conhecimentos dos estudantes em relação à produção de imagens e não de troca de um tipo de imagem por outra.

\section{Considerações finais}

Diante do exposto, entendemos a pertinência de liberarmonos das estruturas canônicas, imutáveis e heterogêneas da história e da arte, feitas sobre o mesmo enfoque e com as mesmas direções. Do mesmo modo, pensando a partir da cultura visual, não interessa pensar no que carregam os elementos visuais e o que querem representar ou dizer, com verdades a serem identificadas, e sim, questionar as interpretações já consolidadas.

- processo de deslocalização do olhar para o que já foi legitimado, implica também o modo com que relacionamo-nos com uma pesquisa a partir da cultura visual, uma pesquisa que se faz pautada pela movimentação subjetiva e constante e não por linhas pré-definidas e inalteráveis. A perspectiva a que se bebe para a construção dessa escrita possibilita fazer considerações sobre diferentes ângulos, sempre que se vê necessário.

De modo igual, no que diz respeito a segunda parte do texto, a partir de uma mesma abordagem, entendemos ser necessário questionar as imagens que se fazem presentes diariamente na vida das crianças. Ouve-se tanto sobre 


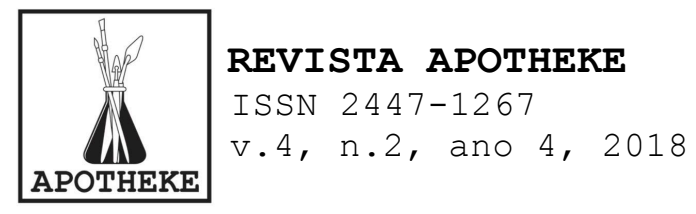

"estudante e cidadão crítico", mas como se vem a ser crítico se as práticas sociais não forem potencializadas? Acreditamos que as mudanças necessárias, tanto de posicionamento, como de olhar, podem nos aproximar de uma visualização/ação crítica, ao menos não passiva diante à mídia. Já que, acreditamos também que o/a professor(a) unidocente, aquele que transita por diversas áreas, em um trabalho interdisciplinar e atento às necessidades dos/as estudantes e às mudanças da sociedade, poderia ter em seu planejamento práticas artísticas e pedagógicas que explorem o universo visual/cultural infantil, esses que podem ser um passo inicial para pensar em posicionamentos críticos frente às imagens.

Trata-se, sobretudo, em ambos os casos, de revisitar imagens e posições com outros modos de discursos, que possibilitem diferentes interpretações e ações. Implica abrir espaço para outras formas de ver e se relacionar com aquilo que se vê e se tem, seja mediante atitudes críticas, reflexivas ou que produzam novas formas de investigação e produção de conhecimentos e significados.

\section{Referências}

BELTING, Hans. O fim da história da arte: uma revisão dez anos depois. São Paulo: Cosac \& Naify, 2006.

BUCKINGHAM, David. Crecer em la era d elos medios electrónicos. Madrid: Ediciones Morata, 2002.

GUASCH, Anna Maria. Doce reglas para uma nueva academia: La <<nueva historia del arte>> y los estúdios audiovisuales. In: Estudios Visuales: La epistemologia de la visualidade em la era de la globalización. Madrid: Akal, 2005, p. 59- 74 .

HERNÁNDEZ, Fernando. Catadores da Cultura Visual: uma proposta para uma nova narrativa educacional. Trad. de Ana Duarte. Editora Mediação, Porto Alegre: 2007.

Pesquisar com imagens, pesquisar sobre imagens: revelar aquilo que permanece invisível nas pedagogias da Cultura Visual. In: MARTINS, Raimundo e TOURINHO, Irene. Processos e Práticas de pesquisa em Cultura Visual e Educação. Santa Maria: Editora da UFSM, 2013, p. 77-95. 


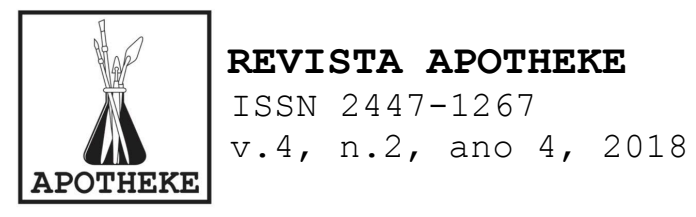

MARTINS, Raimundo; TOURINHO, Irene. Circunstâncias e ingerências da cultura visual. In: MARTINS, Raimundo; TOURINHO, Irene. Educação da Cultura Visual: conceitos e contextos. Ed: UFSM, 2011. P. 51-68.

MIRZOEFF, Nicholas. An introduction to visual culture. London: Routlege, 1999.

MOXEY, Keith. Nostalgia for the real: The troubled relation of the art history to visual studies. In: The Practice of Persuasion: Paradoz and Power in Art History. Ithaca, N.Y.: Coronell University Press, 2001.

NASCIMENTO, Erinaldo Alves do. Singularidades da educação da cultura visual nos deslocamentos das imagens e das interpretações. In: MARTINS, Raimundo; TOURINHO, Irene (Org.). Educação da cultura visual: conceitos e contextos. Santa Maria: Editora UFSM, 2011, p. 209- 226.

SALBEGo, Juliana. Atravessamentos e visualidades em ambientes educativos: aproximações com o PIBID Artes Visuais/UFSM. Tese (Doutorado em Educação), Universidade Federal de Santa Maria, 2017.

Milena Regina Duarte Corrêa -

http: / / buscatextual.cnpq.br/buscatextual/visualizacv. do?id=K8058209H4

Mestranda do Programa de Pós-Graduação em Artes Visuais/PPGART Universidade Federal de Santa Maria, em história, teoria e crítica, linha de Pesquisa Arte e Cultura, bolsista DS/CAPES 2018. Graduada em Artes Visuais Licenciatura Plena pela Universidade Federal de Santa Maria. Atuou como bolsista do Programa Institucional de Bolsa de Iniciação à Docência (PIBID/UFSM), como bolsista do projeto de extensão: Art in Bag: Exposições Itinerantes (FIEX/UFSM) e do projeto de extensão NECCA (PROLICEN/UFSM). Membra do grupo de pesquisa: Artes Visuais e I/Mediações (AVI/CAL) e do Laboratório de Artes Visuais e suas I/Mediações (LAVI/M). Tem interesse nas áreas de cultura visual, história da arte e arte contemporânea.

Jéssica Maria Freisleben -

http://buscatextual.cnpq.br/buscatextual/visualizacv.do?id=K4816471D3

Mestranda em Educação pelo Programa de Pós-graduação em Educação (PPGE) na Linha de Pesquisa LP4 - Educação e Artes. Licenciada em Artes VisuaisLicenciatura Plena em Desenho e Plástica/UFSM. Atuou como bolsista PIBIDPrograma Institucional Bolsas de Iniciação à Docência em Artes Visuais. Foi integrante do Grupo de Pesquisa Artes Visuais e suas I/Mediações e do Ateliê de Pintura 1336. Integrante do projeto de Extensão: e "Arte Contemporânea e Educação da Cultura Visual: Pedagogias na Alfabetização Infantil". Membro do Coletivo de artistas "Capella". 